\title{
CORRECTION
}

\section{Correction to: What is society?}

Juichi Yamagiwa and Shun Hongo (2020) Evolution of human sociality, vol 1. Primatology as a study of society. iCardbook. Shisousha, Tokyo; Juichi Yamagiwa and Shun Hongo (2020) Evolution of human sociality, vol 2. The past, present, and future of a society with empathy and family. iCardbook. Shisousha, Tokyo

\section{Crickette Sanz ${ }^{1}$ (1)}

Published online: 21 December 2020

(c) Japan Monkey Centre and Springer Japan KK, part of Springer Nature 2020

\section{Correction to: Primates (2020) 61:819-820}

https://doi.org/10.1007/s10329-020-00871-w

In the original publication of the article, the name of the book publisher was incorrect. The correct name is "Shisousha".

Publisher's Note Springer Nature remains neutral with regard to jurisdictional claims in published maps and institutional affiliations.

The original article can be found online at https://doi.org/10.1007/ s10329-020-00871-w.

Crickette Sanz

csanz@wustl.edu

1 Department of Anthropology, Washington University in St.

Louis, One Brookings Drive, St. Louis 63130, Missouri,

USA 